International Journal of Nano Studies \& Technology (IJNST)

ISSN 2167-8685

\title{
Self-Assembled Microwires of Aromatic Acids and Melamine
}

Research Article

Wang H, Johnson N, Sagar V, Brooks E, Kopp L, Grimes T, Xu X, Hai-Feng Ji*

* Department of Chemistry, Drexel University, Philadelphia, PA, USA.

\section{Abstract}

Self-assembled micro/nanowires of melamine and seveal aromatic acids, including thiocyanuric acid, trimesic acid, terephthalic acid, and 5-sulfoisophthalic acid, are formed through evaporation of water in a solution mixture of acids and melamine. These self assemblies show crystalline structures. Except for microwires of 5-sulfoisophthalic acid and melamine, other microwires are semiconductors. They may be used for sensors, catalyst, optoelectronics, etc.

Keywords: Nanowires; Microwires; Self-Assembly; Aromatic Acid; Melamine.

\author{
*Corresponding Author: \\ Hai-Feng Ji, \\ Department of Chemistry, Drexel University, Philadelphia, PA, USA. \\ Tel: 01-215-895-2562; Fax: 01-215-895-1265 \\ E-mail: hj56@drexel.edu
}

Received : June 29, 2012

Accepted: August 16, 2012

Published: August 22, 2012

Citation: Hai-Feng Ji, et al (2012) Self-Assembled Microwires of Aromatic Acids and Melamine. Int J Nano Stud Technol, 1(1), 1-5. doi: http://dx.doi.org/10.19070/2167-8685-120001

Copyright: Hai-Feng Ji ${ }^{\odot}$ 2012. This is an open-access article distributed under the terms of the Creative Commons Attribution License, which permits unrestricted use, distribution and reproduction in any medium, provided the original author and source are credited.

\section{Introduction}

With the ultimate objective of the miniaturization of electronic device components, various methods for the fabrication of well-defined nano/microstructures have been extensively studied, not only to improve device performance, but also to take advantage of the remarkable properties of nanostructures that raise new possibilities at the nanoscale. Significant progress has been made in the area of 'supramolecular electronics' that has opened up potential applications in nanoelectronics, sensors, catalysts, etc. The term $[1,2,3,4]$ refers to nano/microstructures, primarily formed by non-covalent interactions, for application as basic electronic components like diodes, transistors, etc. Supramolecular electronics has evolved from using polydisperse systems containing conducting polymers, such as polyaniline, polyacetylene, etc., to using block copolymer strategies and polycyclic aromatic hydrocarbons.[5] The need for higher quantum efficiency in nanoelectronics, control of morphology for ease of fabrication, and convenient design parameters for potential commercialization, fuels the need for identifying new materials.

Formation of multiple hydrogen bonds between complementary organic molecules has recently been exploited for the molecular self-assembly of well-defined artificial supramolecular structures and materials. One of the most widely studied supramolecular systems is prepared from melamine $(\mathrm{M})$ derivatives and various organic acids. $[7,8,9,10]$ Supramolecular systems based on melamine include two-dimensional (2D) epitaxial networks on gold surfaces[11] and molecular assemblies refer to those that are soluble in water or organic media. In our previous work, we assembled an array of well-defined hexagonal nanopillars of cyanuric acid (CA) and melamine complex on a gold surface by means of a solvent evaporation approach.[12] The nanoassemblies could be made in large quantities at a low cost due to the facile method, which makes them competitive for preparing nanostructure-based devices or coatings. In this work, we demonstrate the formation and characterization of the micro/nanowires from melamine and a library of aromatic acids, including thiocyanuric acid (TCA), trimescid acid (TMA), terephthalic acid (TPA), and 5-sulfoisophthalic acid (Figure 1). It's noteworthy that the keto form cyanuric acid and thiocyanuric acid also belong to aromatic acids because they both show aromatic characters. $[13,14]$

\section{Materials and Methods}

\section{Chemicals}

Thiocyanuric acid (TCA), melamine, trimescid acid, terephthalic acid (TPA), and 5-sulfoisophthalic acid (SPA) were purchased from Alfa Aesar or TCI America and were used as received.

\section{Instruments}

Attenuated total reflection infrared (ATR-IR) spectra were recorded on a Smith IR microscope. A Zeiss Supra 50VP was used to obtain scanning electron microscopy (SEM) images. Cross-polarized optical microscopy (CPOM) images were collected on a Smith polarized microscope. The geometric optimization was performed at density functional theory (DFT) B3LYP level with a LANL2DZ basis set. The nanowire device was prepared as the following: A nanowire was transferred on a glass slide, and then an 8 - $\mu$ m-diameter copper wire was placed on the nanowire at a $90^{\circ}$ angle. The copper wire is long enough to reach across the top surface of the glass slide. A 200 nm-thick layer of Pt was sputtered on the glass. After 
Figure 1. Molecular structure of melamine and thiocyanuric acid (TCA), trimescid acid (TMA), terephthalic acid (TPA), and 5-sulfoisophthalic acid (SPA).<smiles>NC1NC(N)NC(N)N1</smiles>

Melamine<smiles>S=c1[nH]c(=S)[nH]c(=S)[nH]1</smiles>

Thiocyanuric acid (TCA)<smiles>O=C(O)c1cc(C(=O)O)cc(C(=O)O)c1</smiles>

Trimesic acid (TMA)<smiles>O=C(O)c1ccc(C(=O)O)cc1</smiles><smiles>O=C(O)c1cc(C(=O)O)cc(S(=O)(=O)O)c1</smiles>

5-sulfoisophthalic acid (SPA)

Table 1. Conditions to form and dimentions of microwires.

\begin{tabular}{|l|l|l|l|l|}
\hline & TCA $^{*} \mathrm{M}$ & TMA $^{*} \mathrm{M}$ & TPA $^{*} \mathrm{M}$ & SPA $^{*} \mathrm{M}$ \\
\hline Concentration & $3 \times 10^{-3} \mathrm{M}$ & $3 \times 10^{-3} \mathrm{M}$ & $1 \times 10^{-3} \mathrm{M}$ & $5 \times 10^{-3} \mathrm{M}$ \\
\hline Ratio & $1: 1$ & $1: 1$ & $2: 3$ & $1: 1$ \\
\hline Max. length & $300 \mu \mathrm{m}$ & $1 \mathrm{~mm}$ & $500 \mu \mathrm{m}$ & $2 \mathrm{~mm}$ \\
\hline Max. dimeter & $4 \mu \mathrm{m}$ & $20 \mu \mathrm{m}$ & $5 \mu \mathrm{m}$ & $30 \mu \mathrm{m}$ \\
\hline
\end{tabular}

sputtering, the strip was removed and the Pt on the two sides of the nanowire acts as the electrodes. I-V curves were measured by using a Keithley 2636A system source meter. The conductivity tests were performed with a micro/nanowire device placed in a glass tube, which is $20 \mathrm{~cm}$ in length and $1.5 \mathrm{~cm}$ in diameter.

\section{Results and Discussions}

The microwires of TCA and melamine were crystallized from water. A $10 \mathrm{~mL}$ sample of $3 \times 10^{-3} \mathrm{M}$ TCA and melamine solution was mixed in a 1:1 ratio in a $V$-shaped vial. The vial was then left alone at room temperature until the volume of the solution had decreased to $0.1 \mathrm{~mL}$. The sample was then filtrated and the solid collected for analysis. Once formed, these wires are very stable in water. They do not disintegrate in water. The approach was also used for growing micro/nanostructures of melamine with other aromatic acids.

Fig. 2. shows a scanning electron microscopy (SEM) image of microwires of melamine - aromatic-acid complexes. Table 1 lists the conditions to form the complexes and dimentions of these microstructures. It's noteworthy that 1) the size of the these complexes can be controlled through concentration of chemicals and evaporation amount of the solvent. Nanowires of the complexes were formed when a small amount of water was evaporated (figures not shown); b) the ratios of the aroamtic acids and melamine are not critical to form the wires.

Fig. 3 shows the infrared spectra of melamine powder, TCA powder and TCA'M microwires. In the IR spectrum of the melamine powder, the major transmission peaks appear at 3500- 3000 and
$1700-1300 \mathrm{~cm}^{-1}$. The peaks at 3472 and $3420 \mathrm{~cm}^{-1}$ are typical $\mathrm{NH}_{2}$ stretch peaks of melamine. The IR peaks of the powder of TCA at 1512,1101 , and $730 \mathrm{~cm}^{-1}$ are the characteristic peaks of the nonaromatic, thirthione form of the triazine ring. [15] Specifically, the peak at $1101 \mathrm{~cm}^{-1}$ is assigned to $\mathrm{C}=\mathrm{S}$ stretching vibration. The peaks at $2897-3166 \mathrm{~cm}^{-1}$ are attributed to N-H stretching vibrations. Compared to the IR peaks of the powder TCA, the $\mathrm{C}=\mathrm{S}$ stretching vibration of the $\mathrm{TCA}^{\circ} \mathrm{M}$ microwires is shifted to a higher wavenumber at $1138 \mathrm{~cm}^{-1}$, indicating the formation of hydrogenbonds between $\mathrm{C}=\mathrm{S}$ in TCA and $\mathrm{NH}_{2}$ in melamine molecules in the microwires, which restrict the stretching vibration and thus increase the vibrational frequency. The appearance of a broad band around $3000 \mathrm{~cm}^{-1}$ is attribute to the inclusion of water molecules in the hydrogen-bound network of melamine and TCA in the microwires. [16,17] Similarly TMA, TPA, and SPA also formed hydrogen bond network with melamine in TMA ${ }^{*} \mathrm{M}$, $\mathrm{TPA}^{\circ} \mathrm{M}$, and $\mathrm{SPA}^{\circ} \mathrm{M}$ microwires, respectively (figures not shown).

$\mathrm{X}$-ray diffraction $(\mathrm{XRD})$ shows that the TMA'M nanowire is crystalline and the lattice indices are $\mathrm{a}=6.93 \AA, \mathrm{b}=11.27 \AA$, and $\mathrm{c}=$ $11.68 \AA$, indicating a triclinic structure of the microwires, which is the same as those plate crystals obtained in organic-aqueous binary solvents [18]. The molecules are oriented with their $\pi-\pi$ stacking direction parallel to the wire. XRD also shows that the SPA ${ }^{*} \mathrm{M}$ wires are crystalline, with a monoclinic structure having lattice indices of $\mathrm{a}=7.5760 \AA, \mathrm{b}=18.1071 \AA$, and $\mathrm{c}=15.0750 \AA$ (Figure 4).

We could not obtaine the crystal structure of the TCA ${ }^{*} \mathrm{M}$ and $\mathrm{TPA}^{*} \mathrm{M}$ microwires so far because the size of prepared mirowires are not large enough for XRD measurement. Our current efforts focus on fine-tuning interaction conditions, such as slower evapo- 
Figure 2. SEM images of microwires of melamine with aromatic acids. Top left: TCA $\bullet$; Top right: TMA $\bullet$ M; Bottom left: TPA $\bullet$ M; Bottom right: SPA $\bullet$ M.
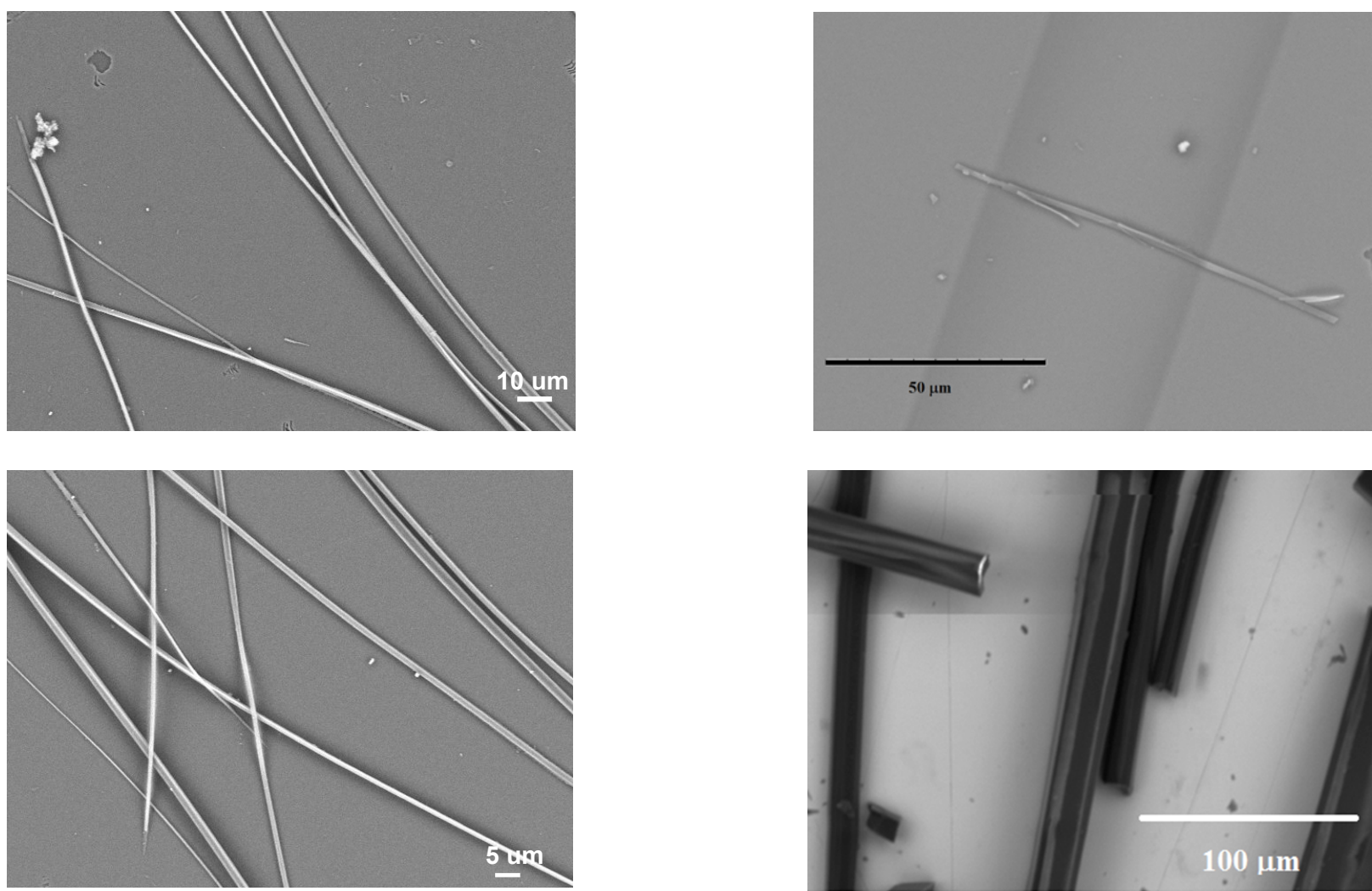

Figure 3. Infrared (IR) spectra of melamine, TCA and TCA $\bullet M$

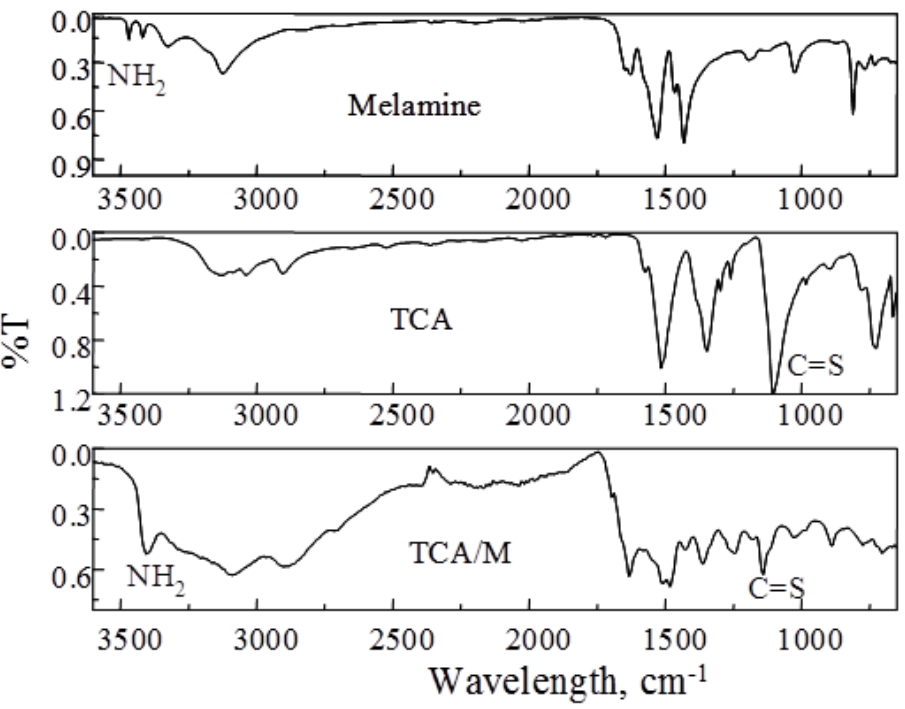

Figure 4. Crystal structrure of SPA-M.

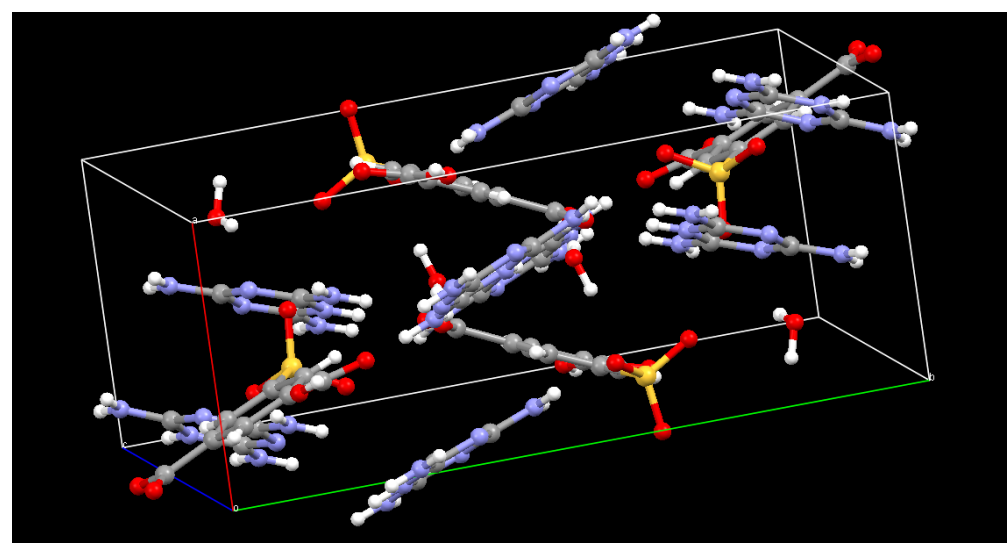


Figure 5. (A). A cross polarized optical microscopy (CPOM) image of TCA'M microwires. (B). Brightness versus the angle between the direction of the polarization light and the long axis of a TCA $^{\circ} \mathbf{M}^{2}$ microwire.

A

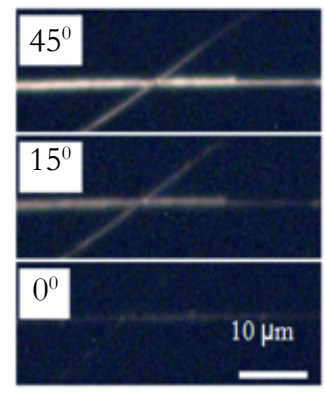

B

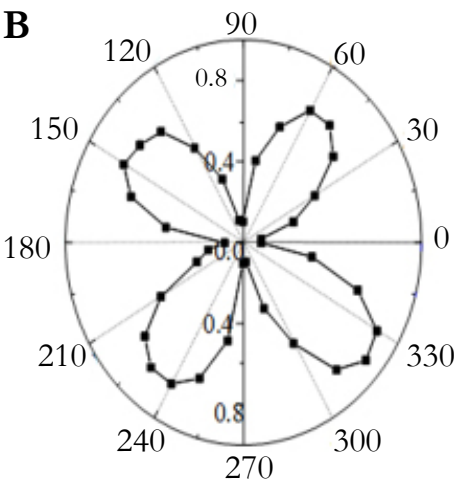

Figure 6. I-V curves of TCA $^{\circ} \mathrm{M}$, TMA $^{\circ} \mathrm{M}$, and TPA'M microwires measured in dry nitrogen.
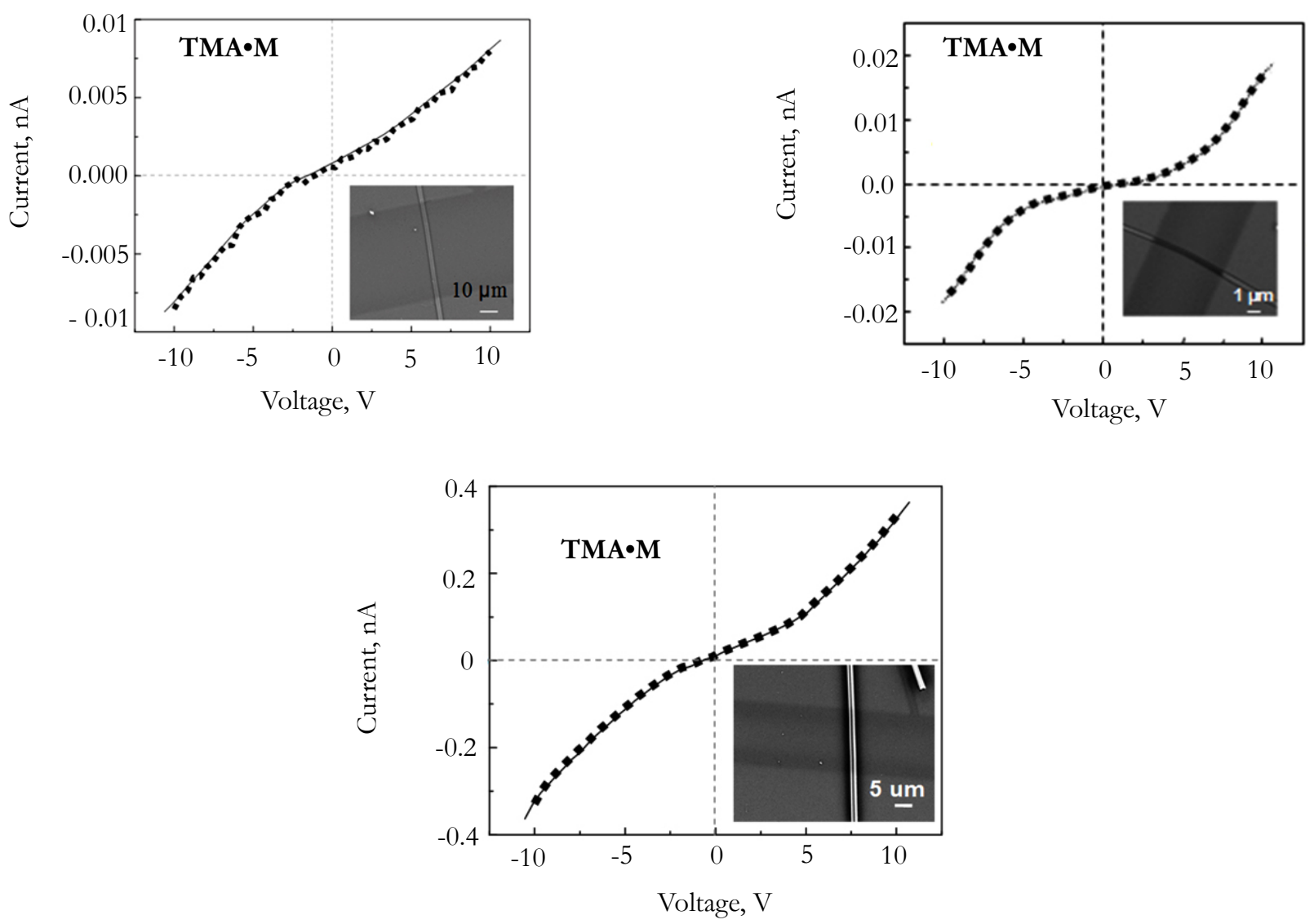

ration and higher concentrations, in order to grow wider wires for XRD. However, although the crystal structures of the TCA ${ }^{*} \mathrm{M}$ and TPA $^{\circ} \mathrm{M}$ microwires are not determined, the crystallinity of these microwires have been confirmed by polarized optical microscopy (CPOM). Figure 5A shows the brightness of CPOM images of $\mathrm{TCA}^{\circ} \mathrm{M}$ microwires on varying the angle between the long axis of the microwire and the polarization light. The brightness increases when the angle increases from $0^{\circ}$ to $45^{\circ}$. The brightness versus the angle (Figur 5B) shows four repeat profiles in a complete circle. The brightness changes from the maximum to the minimum in every $45^{\circ}$. This periodical change of the brightness vs. the angle reveals that the $\mathrm{TCA}^{\circ} \mathrm{M}$ microwire is birefringent crystal, $[19,20]$ in which there are two distinct indices of refraction resulting in the splitting one ray of light into two rays. Similarly TPA also showed crystall- line structures determiend by CPOM (figures not shown).

Figure 6. shows the semiconductive properties of microwires of $\mathrm{TCA}^{\circ} \mathrm{M}, \mathrm{TMA}^{\circ} \mathrm{M}$, andTPA $\mathrm{M}$ in air at ambient condition. The microwires of IPA ${ }^{*} \mathrm{M}$, however, are not conductive, which may due to a lack of $\mathrm{p}-\mathrm{p}$ interaction in the IPA'M microwires as shown in the crystal structure (figure not shown).

In summary, we have prepared a new family of crystalline micro/nanowires, including $\mathrm{TCA}^{*} \mathrm{M}, \mathrm{TMA}^{*} \mathrm{M}$, TPA ${ }^{*} \mathrm{M}$, and SPA $M$, by means of a facile self-assembling process of melamine and a group of aromatic acids. The potential applications of these microwires in sensing, catalyst, and optoelectronics are under investigation and will be reported in due course. 


\section{Acknowledgement}

We thank the support from the National Science Foundation (EEC1138240).

\section{References}

[1]. Schenning, A.P.H.J. and Meijer, E.W. Supramolecular electronics; nanowires from self-assembled p-conjugated systems. Chem. Comm. 2005, 32453258.

[2]. S. C. Zimmerman, F. Zeng, D. F. C. Reichert, C. V. Kolotuchin, Science, 1996, 271, 1095-1098.

[3]. A. P. H. J. Schenning, E. W. Meijer, Chem. Commun., 2005, 41, 32453258.

[4]. G. V. Oshovsky, D. N. Reinhoudt, W. Verboom, Angew. Chem. Int. Ed. 2007, 46, 2366-2393.

[5]. Meijer, E.W. and Schenning, A.P.H.J. Material marriage in electronics. Nature 2002, 419, 353-354.

[6]. a) L R. Macgillivray, J. L. Atwood, Nature 1997, 389, 467-472; b) R. S. Meissner, J. Rebek Jr., J. de Mendoza, Science 1995, 270, 1485-1488; c) S. C. Zimmerman, F. Zeng, D. F. C. Reichert, C. V. Kolotuchin, Science, 1996, 271, 1095-1098; d) R. P. Sijbesma, F. H. Beijer, L. Brunsveld, B. J. B. Folmer, J. J. K. K. Hirschberg, R. F. M. Lange, J. K. L. Lowe, E. W. Meijer, Science, 1997, 278, 1601-1604.
[7]. J. A. Zerkowski, C. T. Seto, D. A. Wierda, G. M. Whitesides, J. Am. Chem. Soc., 1990, 112, 9025-9026.

[8]. C. T. Seto, G. M. Whitesides, J. Am. Chem. Soc., 1993, 115, 905-916;

[9]. C. T. Seto, G. M. Whitesides, J. Am. Chem. Soc., 1990, 112, 6409-6411.

[10]. F. J. M. Hoeben, P. Jonkheijm, E. W. Meijer, A. P. H. J. Schenning, Chem. Rev. 2005, 105, 1491-1546.

[11]. 11. F. Silly, A. Q. Shaw, M. R. Castell, G. A. D. Briggs, M. Mura, N. Martsinovich, L. Kantorovich, J. Phys. Chem. C. 2008, 112, 11476.

[12]. H. F. Ji, X. Xu, "Hexagonal Nanopillars of Melamine-Cyanuric Acid Complex Prepared by A Crystallization After Mixing on Surfaces (CAMS) Method". Langmuir, 2010, 26, 4620-4622.

[13]. L. Perez-Manriquez, A. Cabrera, L. E. Sansores, R. Salcedo, J. Mol. Model. 2011, 17, 1311-1315.

[14]. S. Cermakova, R. Herchel, Z. Travnicek, M. Sebela, Inorg. Chem. Commun., 2010, 13, 778-781.

[15]. W. A. England, M. G. Cross, A. Hamnett, P. J. Wiseman, J. B. Goodenough, Solid State Ionics, 1980, 1, 231-249.

[16]. P. Christian, H. Isabel, K. Karl, N. Eyal, S. V. Mattanjah, Chemphyschem, 2003, 4, 838-842.

[17]. M. M. Habeeb, H. A. Al-Wakil, A. El-Dissouky, N. M. Refat, Spctroscopy, 2001, 15, 33-44.

[18]. X. L. Zhang, X. M. Chen, Cryst. Growth Des. 2005, 5, 617-622.

[19]. D. H. Kim, J. T. Han, Y. D. Park, Y. Jang, J. H. Cho, M. Hwang, K. Cho, Adv. Mater 2006, 18, 719.

[20]. W. Pisula, M. Kastler, D. Wasserfallen, T. Pakula, K. Mullen, J. Am. Chem. Soc. 2004, 126, 8074. 